\title{
EKSPRESI LITERASI PETUAH BIJAK PADA MAN 1 BONE DAN MAS AL-JUNAEDIYAH BIRU BONE
}

\section{THE EXPRESSION OF LOCAL WISDOM MESSAGE AT STATE OF ISLAMIC SENIOR HIGH SCHOOL AND AL-JUNAIDIYAH PRIVATE SCHOOL IN BONE REGENCY}

\author{
Muh. Subair \\ Balai Penelitian dan Pengembangan Agama Makassar \\ Kantor: Jl.A.P. Pettarani No. 72 Makassar \\ e-mail: ingatbair@gmail.com
}

Naskah diterima tanggal 26 September 2017. Naskah direvisi 7 Oktober 2017. Naskah disetujui 30 Oktober 2017.

\begin{abstract}
Abstrak
Nyanyian "ala massea-sea" mengandung petuah bijak yang mengajak untuk "sesal dahulu perbuatan sesal kemudian tiada guna". Lagu ini juga meninggalkan pesan tentang kisah seorang yang putus asa dalam belajar, ketika melihat tetesan air dalam gua yang dapat menembus batu, membuatnya sadar betapa keuletan dapat menembus benda sekeras apapun. Sehingga, ia pun kembali belajar dengan tekun hingga sukses menjadi orang terpelajar. Melalui pesan bijak pula, siswa pada MAN 1 Bone dan MAS PMJ Bone dapat kembali mengingat Kajao Laliddong sebagai seorang cerdik pandai yang kritis tetapi juga sopan. Pada artikel ini juga tersaji petuah bijak yang dapat digunakan untuk pengembangan budaya literasi, sebagaimana terhimpun dari hasil FGD, wawancara, observasi dan studi literatur yang dilakukan di MAN 1 Bone dan MAS PMJ Bone. Sebuah hasil penelitian kualitatif yang diuraikan secara deskriptif naratif, yang dilakukan atas dasar fakta memudarnya pesona budaya literasi siswa yang ditandai dengan perbendaharaan petuah bijak yang diketahui oleh siswa, dibandingkan dengan banyaknya petuah bijak yang sarat dengan pesan moral dari warisan leluhur sebagaimana terdapat dalam kitab silasa' dan kumpulan ungkapan I Lagaligo.
\end{abstract}

Kata kunci: ekspresi, petuah bijak, literasi, Bone

\begin{abstract}
The song ala massea-sea contains the wisdom message that invites to regrets earlier acts of regret then no use. This song also left a message about the story of a desperate in learning, when looking at the water droplets in the cave that can pierce the rock, made him realize how toughness can penetrate objects as hard as anything. So he went back to study diligently to become a successful man. Through a wise message, students at MAN 1 Bone and MAS PMJ Bone can recall Kajao Laliddong as a critically clever but polite clever. In this article also presented a wise advice that can be used for the development of literacy culture, as compiled from FGD results, interviews, observations and literature studies conducted in MAN 1 Bone and MAS PMJ Bone. A qualitative research results described descriptively narrative, which is done on the basis of the fact of waning the cultural charm of the students' literacy characterized by the wisdom treasures known by the students, compared to the many wise suggestions laden with the moral messages of the ancestral heritage as contained in the book of silasa 'and the collection of I Lagaligo's expression.
\end{abstract}

Keywords: expression, wise message, literacy, Bone

\section{PENDAHULUAN}

Bukan rahasia, jika dewasa ini siswa/pelajar Indonesia banyak yang terjerumus dalam perilaku kenakalan yang melampaui batas. Bahkan, keterbukaan informasi selepas era reformasi menyebarkan berbagai macam keburukan siswa yang tampil semakin berani. Kondisi ini tentu bertentangan dengan karakter bangsa yang beragama dan berbudaya, di mana siswa seharusnya menjadi lahan subur tumbuhnya nilai-nilai luhur dari budaya leluhur yang bahkan telah diabadikan dalam pancasila. Seyogyanya nilai budaya tersebut, 
sebagai nilai yang sarat dengan petuah bijak, tidak hanya abadi dalam dasar negara, tetapi juga dapat tumbuh dan lestari dalam jiwa-jiwa siswa. Sebab prinsip-prinsip hidup dari petuah bijak diyakini dapat membuat siswa untuk bisa mengantisipasi, menyaring, bahkan mentransformasikan berbagai bentuk pengaruh budaya dari luar.

Petuah bijak adalah kata lain dari parade kearifan lokal yang terbentang di sepanjang khazanah budaya nusantara, pada dasarnya ia adalah folklor lisan yang dapat dijumpai dalam bentuk pantun, peribahasa, motto, dan berbagai bentuk parafrase dengan pesan-pesan tertentu seperti, "berakit-rakit ke hulu, berenang-renang ke tepian, barsakit-sakit dahulu, bersenang-senang kemudian". Atau ungkapan bersatu kita teguh, bercerai kita runtuh, yang di beberapa daerah bisa berbunyi; sagilik saguluk sabayantaka (Bali), pela gandong (Ambon), marimoi ngone future (Ternate), pokadulu (Muna) situlu-tulung (Mandar). Hal ini menggambarkan bahwa kearifan nasional sebagian atau seluruhnya adalah kumpulan kearifan lokal itu sendiri, dan membuat posisi kearifan lokal semakin memiliki nilai tambah, sebab ia juga dievokasi melalui khazanah kebudayaan sendiri yang original dari milik leluhur, sehingga pesan-pesan luhur yang terkandung di dalamnya, bisa menjadi solusi untuk mengantisipasi berbagai kecenderungan negatif yang kini semakin banyak terjadi dalam masyarakat (Ratna, 2011: 92-95).

Petuah bijak tidak seharusnya hanya berhenti pada pengetahuan lokal yang pernah digunakan sebagai penopang kehidupan masyarakat masa lampau, yang kemudian disebut tradisi, tradisional, lama, kearifan lokal dan berbagai padanannya, yang juga tidak harus diartikan sebagai sesuatu yang sudah lewat, ketinggalan zaman, atau tidak sesuai dengan zaman modern (Ratna, 2011: 92, 142).

Selain menonjolnya persoalan kenakalan remaja, Indonesia juga masih sering disoroti sebagai bangsa yang memiliki budaya literasi yang buruk. Hasil survey Programme for International Student Assesment (PISA) 2012 pada bidang literasi atau kemampuan membaca dan menulis Indonesia menempati urutan ke 64 dari 65 negara (Lia,2015: 132). Demikian juga, hasil penelitian PISA tahun 2015 menyebutkan bahwa kemampuan membaca siswa di Indonesia menduduki urutan ke-69 dari 76 negara yang disurvei. Hasil itu lebih rendah dari Vietnam yang menduduki urutan ke-12 dari total negara yang disurvei (http://m.harianjogja.com, diunduh, 22/03/2016). Survey PISA ini, bukan hanya mengindikasikan bahwa prestasi literasi sains siswa di Indonesia, masih lebih rendah dibandingkan dengan negara partisipan yang lain, akan tetapi menandakan juga bahwa siswa di Indonesia masih belum mampu mengkaitkan pelajaran yang mereka dapatkan di sekolah dengan kehidupan sehari-hari. Dengan kata lain siswa Indonesia belum mampu mengkaitkan konten yang mereka pelajari dengan konteks yang berkaitan dengan konten tersebut (Syukran, 2014: 1-2).

Seperti sebuah pukulan jurus pamungkas, siswa kita tampak meradang dengan luka kenakalan yang meningkat dan kondisi literasi yang memburuk. Jurus petuah bijak bukanlah dimaksudkan sebagai pukulan balasan yang dapat mengatasi kedua masalah tersebut sekaligus secara tuntas. Namun, potret kenakalan siswa yang dikemukan di awal hanya sebagai pengantar untuk menegaskan pentingnya petuah bijak bagi siswa, dan indikasi ketergerusan budaya perlu ditelusuri lebih jauh dengan melihat keberadaan petuah bijak yang ada dalam dunia siswa. Sehingga petuah bijak tetap menjadi fokus pengamatan untuk diinventarisir, dan selanjutnya diidentifikasi tentang petuah bijak apa saja yang dapat mendukung dan mengembangkan budaya literasi siswa.

Petuah bijak adalah tradisi yang bisa dianggap dapat memberi arti hidup dan memperteguh kepribadian bangsa. Ia seyogyanya tumbuh mekar di taman jiwa siswa bilamana sekolah atau madrasah masih dilambangkan sebagai sentrum peradaban. Akan tetapi kenyataannya, citra siswa di era kekinian telah didera oleh isu kenakalan dan bahkan dinilai buruk dalam budaya literasi. Kondisi ini menimbulkan tanya, tentang bagaimanakah sesungguhnya wajah petuah bijak yang kini berkembang dalam dunia siswa, dan bagaimana itu dapat dimanfaatkan. Karena itulah problem penelitian ini dititik beratkan pada, Bagaimana petuah bijak itu dimanfaatkan oleh siswa MA untuk pengembangan budaya literasi?.

\section{Tinjauan Pustaka}

Petuah bijak yang dimaksud di sini adalah folklor lisan yang terdapat dalam dunia siswa Madrasah Aliyah, yang mengandung pesan atau nilai luhur berupa; ungkapan, peribahasa, kata mutiara, motto, nyanyian, dan puisi. Sedangkan budaya literasi bukan hanya soal baca-tulis dalam aspek kebahasaan. Namun lebih dalam lagi adalah; kemampuanberpikir kritis, dapat menghitung, memecahkan masalah, cara untuk mencapai 
tujuan, mengembangkan ilmu pengetahuan dan potensi seorang siswa. Atas definisi ini maka yang menjadi fokus pengamatan adalah petuah bijak apa saja yang diketahui oleh siswa dari berbagai sumber, dan petuah bijak apakah yang memotivasi mereka untuk mengembangkan budaya literasi. Selanjutnya, ekspresi petuah bijak siswa lebih jauh dieksplorasi untuk mendapatkan gambaran tentang bagaimana seharusnya petuah bijak dapat mendorong pengembangan budaya literasi siswa.

Penelitian terkait petuah bijak sudah pernah dilakukan oleh Balai Penelitian dan Pengembangan Agama Makassar, dengan judul "Nilai-nilai Keagamaan dalam Petuah Bijak, Puisi dan Peribahasa se Kawasan Timur Indonesia”. Hasil penelitian ini mengungkap petuah bijak dari beberapa daerah di KTI sebagai berikut; 1). Nilai-nilai keagamaan pada kelong Makassar, oleh Muhammad As'ad. 2). Akhlak pemimpin dalam Tuja'I penganugrahan gelar adat pulanga di Gorontalo, oleh Husnul Fahimah. 3). Rukun islam dalam kalindaqdaq, oleh Idham. 4). Nilai keagamaan dalam lagu daerah Kaili Sulawesi Tengah, oleh Muh Subair. 5). Artikulasi religi sajak-sajak persaudaraan Ambon, oleh Abu Muslim. 6). Paiya Lohungo lopoli, petuah bijak dalam pantun Gorontalo, oleh Paisal. 7). Nilai keagamaan dalam tevai ntoutua pada etnis Kaili di Kota Palu, oleh Muhammad Sadli Mustafa. 8). Nilai-nilai Keagamaan dalam sengo-sengo di Mambi Mamasa Sulbar, oleh La Mansi. Hasil penelitian ini menunjukkan varian petuah bijak dari berbagai daerah dalam wujud kearifan lokal.

Sedangkan penelitian terkait literasi antara lain dilakukan oleh Priatno dengan judul "Analisis Literasi Kritis Puisi Puisi Taufik Ismail Dalam Kumpulan Puisi Malu (Aku) Jadi Orang Indonesia Yang Merepresentasikan Kekuasaan Dan Memanfaatannya dalam Pembelajaran Puisi di SMA Negeri 1 Damangan Purwakarta". Literasi yang dimaksud dalam penelitian ini adalah kemampuan memahami kode dalam teks puisi, menganalisis dan mentransformasi teks puisi untuk menambah wawasan pengetahuan. Jadi Literasi digunakan sebagai metode analisis. Analisis Literasi Kritis adalah sebuah cara memahami dan mengapresiasi puisi dengan meyakini bahwa dalam menginterprestasi teks puisi diperlukan sikap kritis, yaitu pemahaman bahasa sebagai kontruk sosial karena memiliki ideologi tertentu untuk diketahui (Priatno, 2013: 8). Adapun literasi siswa dalam proposal ini bukan sebagai metode analisis sehingga hasil penelitian ini tidak dikemukakan lebih banyak karena dianggap tidak terlalu relevan.

Literasi yang relevan dengan penelitian ini adalah tulisan dari Esti Swatika Sari dengan judul: "Mengoptimalkan Kembali Literasi Sastra Di Perguruan Tinggi, Perlukah?". Ia mengatakan bahwa Literasi sastra merupakan kemampuan membaca dan menulis sastra, bagai sebuah keutuhan keterampilan sastra, kemampuan membaca dan menulis sastra perlu diperhatikan. Tidak hanya sebagai bagian dari pengetahuan yang menjadi bagian dari aktivitas akademik, akan tetapi literasi sastra diharapkan dan seharusnya mampu menjadi modal bagi mahasiswa untuk menggali dan mengembangkan potensi dalam berapresiasi sastra. Kegiatan literasi sastra menjadikan mahasiswa sebagai kaum melek sastra atau literet sastra. Beragam aktivitas dapat digali sedemikian rupa untuk membangun sebuah kondisi yang menyenangkan saat berliterasi sastra, baik dengan menggunakan metode maupun media perkuliahan. Setidaknya mengoptimalkan kembali literasi sastra di perguruan tinggi masih dipandang perlu untuk dilakukan (Swatika, 2015: 226).

Penelitian lain adalah Latifah dengan judul "Analisis Literasi Media Televisi Dalam Keluarga. Studi Kasus Pendampingan Anak Menonton Televisi di Kelurahan Sempaja Selatan Kota Samarinda". Berdasarkan hasil penelitian dan pembahasan, dapat diketahui bahwa literasi media televisi keluarga masih ada tingkat awal, dimana pengetahuan dan keterampilan orangtua mengenai media masih pada pengetahuan jenis, kategori, fungsi, dan pengaruh media televisi. Demikian pula pada pendampingan anak dilakukan dengan dua cara, yaitu pertama, pembatasan jam menonton dan pemilihan isi program tv. Kedua, melalui diskusi dan bertukar pikiran dengan anak, sebelum, saat, ataupun setelah menonton tv. (Latifah, 2014: 259).

Suyono melakukan sebuah penelitian yang lebih dekat lagi dengan literasi yang dimaksudkan dalam penelitian ini. Ia mengungkapkan bahwa literasi dapat dijadikan sebagai basis pengembangan pembelajaran efektif dan produktif di sekolah. Konteks yang mendasarinya adalah literasi memungkinkan siswa banyak membaca dan trampil mencari dan mengolah informasi, serta kemampuan siswa membaca dan menulis menjadi berkembang. Selain itu, siswa terampil menghubungkan dan mengintegrasikan materi pelajaran yang diperoleh, lancar mengembangkan gagasan, memahami dan memecahkan masalah dan pada akhirnya dapat 
menguasai kompetensi pembelajaran dengan baik. (Suyono, 2009: 214)

Posisi penelitian petuah bijak dalam literasi siswa adalah penelitian dengan fokus yang lebih jauh akan melihat bagaimana literasi menggugah perasaan siswa. Sehingga penelitian terdahulu yang terkait literasi akan dijadikan sebagai pendukung dan penguat, dimana fakta-fakta yang dikemukakan sangat mendukung adanya literasi sebagai sumber inspirasi nilai-nilai luhur, petuah bijak dan merupakan modal bagi siswa untuk mengembangkan potensi dirinya dan menguatkan kepribadiannya.

Petuah bijak adalah istilah lain dari folklor lisan yang terdiri atas; 1) ungkapan tradisional, (pepatah, peribahasa, semboyan). 2) nyanyian rakyat. 3) bahasa rakyat berupa dialek, julukan, sindiran, bahasa rahasia, bahasa remaja, dan sejenisnya. 4) teka-teki (berbagai bentuk tanya jawab pada umumnya untuk mengasah pikiran). 5) cerita rakyat; mite, legenda, sage (Hutomo, 1991: 8).

Petuah bijak dalam bahasa lain disebut saying, yaitu; A saying is any concisely written or spoken linguistic expression that is especially memorable because of its meaning or structure. Terdiri atas: 1) Aphorism,petitih yang mengandung kebenaran umum dan dapat diamati, petitih yang bernas tentang kearifan dan kebenaran). 2) Apophthegm, ekspresinya menganggu, beraroma aforisme sinis.

3) Cliché or bromide, kata-kata yang dianggap klise. 4) Platitude, kata-kata klise yang berhasil disajikan, seolah-olah itu benar-benar bermakna, asli, atau efektif. 5) Epigram, petitih yang ditulis dengan pintar, bermatra puitik, yang isinya adalah komentar terhadap pada orang, ide, atau hal tertentu. 6) Epitaph, petitih untuk menghormati orang yang telah meninggal, sering terukir di batu nisan. 7) Epithet, petitih deskriptif atau petitih yang .dikaitkan dengan orang, ide, atau hal tertentu). 8) Idiom, petitih yang hanya memiliki interpretasi non-literal; "Ungkapan yang maknanya tidak dapat diturunkan hanya dengan mendengarnya. 9) Mantra, petitih spiritual keagamaan, mistis, diekspresikan secara berulang, misalnya, dalam meditasi. 10) Maxim or gnome, (1) petitih yang bersifat instruksional terhadap prinsip umum atau untuk kode perilaku ; atau , (2) petitih. 11) Motto, petitih yang sering digunakan oleh orang atau kelompok untuk secara ringkas menyatakan pandangan dunianya, world view. 12) Quip, petitih pintar atau jenaka yang didasarkan pada pengamatan. 13) Witticism, petitih pintar, jenaka, terkenal karena bentukmya atau gayanya melebihi isinya (Alwy Rachman, 2016: 2-3).

Folklor sering diidentikkan dengan istilah tradisi lisan dan sastra lisan. Karena itu perlu dijelaskan kembali bahwa folklore adalah kata majemuk, yang berasal dari dua kata dasar folk dan lore. Folk sama artinya dengan kata kolektif (collectivity). Menurut Alan Dundes, folk adalah sekelompok yang memiliki ciri-ciri pengenal fisik, sosial, dan kebudayaan, sehingga dapat dibedakan dari kelompok-kelompok lainnya. Namun yang lebih penting adalah bahwa mereka telah memiliki suatu tradisi, yakni kebudayaan yang telah mereka warisi turun-temurun, sedikitnya dua generasi, yang dapat mereka akui sebagai milik bersama. Dan yang penting lagi, mereka sadar akan identitas kelompok mereka sendiri. Lore adalah tradisi folk, yaitu sebagian kebudayaannya, yang diwariskan secara turun-temurun secara lisan atau melalui suatu contoh yang disertai dengan gerak isyarat atau alat pembantu pengingat mnemonic device. Definisi folklor secara keseluruhan: folklor adalah sebagian kebudayaan suatu kolektif, yang tersebar dan diwariskan turun-temurun, di antara kolektif macam apa saja, secara tradisional dalam versi yang berbeda, baik dalam bentuk lisan maupun contoh yang disertai dengan gerak isyarat atau alat pembantu pengingat, mnemonic device (Danandjaja, 2007: 1-6).

Alat pembantu pengingat, selain bebentuk mnemonic device juga dapat dideteksi dalam bentuk citra arketip, yaitu mengarahkan perilau, khususnya yang berkaitan dengan pikiran dan perasaan tidak langsung, seperti cita-cita dan kehendak, kreasi dan imajinasi, khususnya perilaku yang berkaitan dengan pengalaman. Dengan dasar warisan nenek moyang, arketipe berfungsi sebagai prototype, cetak biru pola-pola perilaku individu. Pada bagian ini dapat diidentifikasi pengalaman yang berulangulang berkaitan dengan jejak-jejak tokoh atau hero baik merupakan ekspresi dalam mitos dan ritual (Ratna, 2011: 92, 142).

Karena itu, folklor dan tradisi lisan yang diistilahkan sebagai petuah bijak dalam makalah ini akan sangat terkait dengan budaya literasi, ia sesungguhnya lahir dari evokasi budaya atau pengalaman hidup masyarakat masa lampau. Sedangkan pengalaman-pengalaman masa lalu akan sangat berharga untuk bekal hidup orang-orang terkini, dimana pengalaman-pengalaman tersebut dapat ditemui dalam sastra lisan yang juga banyak dijumpai dalam karya sastra yang bermutu. Pada 
gilirannya, tradisi masyarakat yang dapat diserap sebagai sebuah pengalaman, juga dapat mendorong terciptanya kesadaran budaya literasi yang lebih kuat

Literasi adalah kemampuan kolaboratif/ sinergis berbahasa dan berpikir dengan inti kegiatan membaca-berpikir-menulis yang dilakukan oleh seseorang (siswa) dalam rangka memanfaatkan secara optimal berbagai sumber baik yang tercetak maupun yang tidak tercetak untuk berbagai keperluan. Literasi akademik siswa di sekolah adalah proses mengembangkan budaya literasi di sekolah, artinya pengembangan kesadaran, motivasi, keterampilan, kegemaran berliterasi yang tinggi dari siswa di sekolah untuk keperluan akademik maupun non-akademik. Literasi akademik adalah pemanfaatan dari sinergi kemampuan membaca, berpikir-kritis, menulis yang diterapkan secara lintas bidang studi (Kusumo, 2013: 1).

Makna literasi semakin berkembang dari waktu ke waktu. Perkembangan makna tersebut mengikuti perkembangan zaman yang bergerak cepat. Perkembangan zaman yang pesat jugalah yang membukakan tirai penutup literasi. Sekarang kita tahu bahwa literasi tak melulu baca-tulis. Literasi adalah praktik kultural yang berkaitan dengan persoalan sosial dan politik. Oleh karenanya para pakar pendidikan dunia berpaling kepada definisi baru tentang literasi. Selain itu, dewasa ini kata literasi banyak disandingkan dengan kata-kata lain, misalnya literasi komputer, literasi virtual, literasi matematika dan sebagainya. Hal tersebut merupakan transformasi makna literasi karena perkembangan zaman. Oleh sebab itu, Freebody dan Luke menawarkan model literasi sebagai berikut:

a. Memahami konteks dalam teks: mengenali dan menggunakan fitur seperti alfabet, suara, ejaan, konvensi dan pola teks.

b. Terlibat dalam memaknai teks: memahami dan menyusun teks tertulis dan teks virtual dan lisan yang berati dari budaya tertentu, lembaga, keluarga, masyarakat, negara-negara dan lainlain. Menggambarkan skema yang ada.

c. Menggunakan teks secara fungsional.

d. Melakukan analisis dan mentransformasikan teks secara kritis: memahami dan bertindak atas pengetahuan bahwa teks-teks tidak netral. Teks mewakili pandangan tertentu, diam, mempengaruhi ide-ide orang. Desain teks dan wacana dapat dikritik dan didesain ulang dengan cara baru dan hibrida.
Keempat peran literasi ini dapat diringkas kedalam lima verba: memahami, melibati, menggunakan, menganalisis dan mentransformasikan teks (Rekayasa Literasi : 160).

\section{METODE PENELITIAN}

Penelitian ini merupakan penelitian deskreptif kualitatif dengan melakukan teknik pengumpulan data melalui: 1) Observasi terhadap lingkungan siswa Madrasah Aliyah yang menjadi sasaran penelitian; 2) FGD dan Wawancara dengan informan yang relevan, selain kepada siswa MA, juga dilakukan kepada guru, kepala sekolah dan orang tua siswa, yang dilakukan secara mendalamsampai data yang deperoleh menjadi jenuh; 3) Studi pustaka dan dokumen juga dilakukan berkaitan dengan petuah bijak dan budaya literasi siswa MA.

Data yang akan dikumpulkan dalam penelitian ini mengenai data tentang varian petuah bijak pada siswa Madrasah Aliyah yang meliputi: petuah bijak apa saja yang berada di dunia siswa MA, makna petuah bijak yang berkaitan dengan budaya literasi siswa, dan bagaimana petuah bijak dapat digunakan untuk pengembangan budaya literasi siswa.

Penelitian ini dilaksanakan di Bone Sulawesi Selatan. Pemilihan lokasi dilakukan berdasarkan pertimbangan rekomendasi dari hasil workshop soft skillkarya sastra religi. Di mana siswa yang mengikuti workshop tersebut, telah merepresentasikan tingkat kesadaran budaya literasi siswa dari Madrasah Aliyah yang cukup baik pada lokasi yang di pilih. Sehingga upaya melacak petuah bijak yang dapat digunakan untuk mengembangkan budaya literasi diyakini sudah tepat sasaran.

Data yang terkumpul selanjutnya akan dianalisis dengan menggunakan paparan analisis yang bersifat deskriptif naratif. Deskripsi dilakukan terhadap fakta-fakta dari berbagai sumber data, dan dikemukakan dengan cara naratif tanpa mengubah subtansi data. Hal ini bertujuan untuk menghasilkan suatu gambaran sistematis, faktual, dan akurat mengenai fakta-fakta, sifat-sifat, serta hubungan antar fenomena.

\section{PEMBAHASAN}

\section{Bahasa di Kota Bone Sebagai Basis Petuah Bijak}

Tak lagi mengerutkan dahi jika siswa daerah tingkat kabupaten tidak menggunakan bahasa daerah sebagai percakapan sehari-hari. Meskipun daerah tersebut masih sangat mayoritas dari suatu suku tertentu. Sepertihalnya di Kota Bone yang mayoritas dari suku Bugis, para siswa sudah lumrah menggunakan bahasa Indonesia sebagai bahasa 
sehari-hari. Mungkin awalnya tuntutan berbahasa Indonesia yang baik dan benar berawal dari dalam lingkungan sekolah, yang kemudian mengerucut menjadi sebuah tuntutan kepada setiap keluarga untuk menyiapkan calon peserta didik yang sudah dapat menguasai bahasa Indonesia sejak dini. Kebiasaan berbahasa daerah di lingkungan keluarga pun semakian menguat dari awalnya mengenalkan bahasa Indonesia kepada anak-anak menjadi suatu kebiasaan untuk selalu berbahasa Indonesia dalam keseharian.

Bahasa Indonesia memang penting sebagai lambang persatuan dan alat pemersatu bangsa. Akan tetapi tidak berarti bahwa Bahasa Daerah menjadi diabaikan dan bahkan mulai ditinggalkan oleh penuturnya. Bahasa Bugis sebagai bahasa dari suku besar yang ada di Bone mungkin masih sangat jauh dari ancaman ditinggalkan oleh penuturnya, tetapi gejala penggunaan bahasa Indonesia sehari-hari kepada anak-anak usia sekolah yang berkembang dalam keluarga di kota Bone lambat laun akan menggeser Bahasa Bugis sedikit demi sedikit. Namun semoga saja, pola ini bertahan dimana meskipun massif penggunaan bahasa Indonesia kepada anak, akan tetapi Bahasa Bugis tetap digunakan dalam interasksi kepada sesama orang Dewasa dalam keluarga maupun kepada tetangga dan lingkungan yang lebih luas. Sehingga dari sini anak-anak Bugis tetap mendengar bahasa daerahnya dalam keseharian, meskipun tidak ditujukan kepada mereka secara langsung.

Dapat dikatakan bahwa generasi Bugis dalam lingkungan sekolah kota Bone saat ini adalah mereka yang kebetulan mengetahui bahasa Daerahnya dari hanya mendengar-dengar saja. Hal ini tidak dipandang salah dan seharusnya itu disebut sebuah pembelajaran yang natural. Tetapi dalam hal ini juga seolah tampak bahwa niatan para orang tua tidak lagi dalam posisi menanamkan Bahasa Bugis beserta nilai-nilainya. Bahasa Bugis diperkenalkan sekedar sebagai identitas kepemilikan dan keberpihakan. Segala macam tatakrama dan filosofi bijak yang harusnya melekat dalam praktik berbahasa Bugis tidak begitu dipermasalahkan. Ungkapan tabek yang masih tersisa tidak lagi disertai dengan prilaku takzim dengan menundukkan badan dan pandangan. Terkadang seorang anak malah terkesan meneriakkannya tabek dan lalu malah terkesan menantang dengan tatapan yang jelalatan dan badan yang tak lagi dibungkukkan, bahkan ada yang mengucapkannya sambil begitu tergesa-gesa, setengah berlari, bahkan berlari dan menabrak orang yang di tabekinya. Kedekatan orang tua dan kasih sayang terhadap anak menempatkan prilaku yang mentabek secara tidak takzim dan kering dari nilai moral ini sebagai tindakan yang mudah dimaafkan dan dimaklumi.

Kota Bone sebagai sebuah wilayah basis kerajaan tempat lahirnya para pembesar yang masih sangat masyhur namanya bagi anak-anak Bugis, seperti Arung Palakka dan Kajao Laliddong. Diharapkan masih sebagai wilayah dengan warisan kebudayaan yang melekat bagi anak-anak Bugis, warisan budaya tersebut dapat ditandai diantaranya pengenalan mereka terhadap budaya khas lokalnya khususnya bagi siswa Madrasah Aliyah.

\section{Varian Petuah Bijak siswa Madrasah Aliyah di Kota Bone}

Penelusuran petuah bijak Bugis kepada siswa Madrasah Aliyah di Kabupaten Bone, pada akhirnya akan tampak apakah akan sesuai dengan kondisi penggunaan bahasa Daerah Bugis dalam keseharian mereka, atau tidak. Sebagaimana digambarkan sebelumnya bahwa bahasa Bugis tidak lagi menjadi menu utama dalam interaksi antara orang tua dan anak-anaknya. Sehingga transfer pengetahuan kearifan Bugis pun terlihat begitu minim. Dari 20 kelas MAN 1 Bone yang mempunyai sebanyak 28 kelas dengan jumlah siswa 927 orang, setiap kelas yang kami masuki tidak pernah lebih dari 5 orang yang angkat tangan untuk menjawab pertanyaan, siapa diantara siswa yang ada mengetahui petuah bijak Bugis. Mereka yang angkat tangan pun pengetahuannya sangat standara pada petuah bijak yang sangat popular saja, yaitu taro ada taro gau, dan hanya yang mempunyai pengetahuan petuah bijak selain (taro ada...) itulah kemudian yang terpilih menjadi peserta focus group discussion (FGD) yang kami lakukan. Ada 8 orang laki-laki yang kami pilih setelah memasuki 20 kelas tersebut, dan perempuan hanya 5 orang saja. Selain itu saya juga memilih pengurus organisasi sanggar kesenian, pramuka, dan semua organisasi lainnya di MAN 1 dalam sebuah FGD yang lain.

Pemilihan peserta FGD dilakukan berbeda pada MA Pesantren Modern Aljunaediyah Biru (PMJ) Bone, dimana pada saat merencanakannya guru atau pembina yang dianggap sangat tau dengan kondisi santrinya, tidak ingin kelasnya dimasuki satu per satu karena dianggap mengganggu proses belajar yang sedang berlangsung, karenanya ia memilih siapa-siapa yang dinilai mempunyai pengetahuan tentang petuah bijak Bugis, delapan 
orang peserta FGD untuk santri banin (laki-laki) dan delapan santri banat (perempuan), yang kemudian dijadwalkan FGDnya dalam dua tahap. Setelah FGD kepada para siswa dan santri, dilakukan juga wawancara kepada guru-guru dan selanjutnya wawancara juga dilakukan kepada tokoh sastrawan Bugis untuk mengkonfirmasi petuah-petuah Bugis yang telah dihimpun dari siswa dan santri.

Adapun petuah bijak yang dapat dihimpun berdasarkan pengetahuan siswa pada Madrasah Aliyah Negeri (MAN) 1 Bone dan santri Madrasah Aliyah Swasta MAS PMJ Bone adalah sebagai berikut:

\section{Petuah Bijak Putra MAN 1 Bone}

a. Malebbi kedo ale, malebbi watakkalae, malebbi ada-ada/Baik perilaku, baik rupa, dan baik kata-kata.

b. Taro ada taro gau/Jika bertutur maka bertindak.

c. Aja mulao cemme narekko teako marica/Jangan mandi kalau tak ingin basah.

d. Taroni metti narekko puramui rede/Biar tandas asal sudah mendidih

e. Sipakalebbi sipakatau/Saling memuliakan saling menghargai

f. Purennu cede napole maegae/syukuri yang sedikit malah datang yang lebih banyak

g. Aja muabbola ri wirinna tasie narekko de muelo nakenna bombing/Jangan buat rumah di pinggir laut jika tak ingin terkena ombak.

h. Maega gutturu na de bosinna/Banyak Guntur tapi taka da hujan

i. Magello abbuna magello jajinna/Baik cara membuatnya baik pula hasilnya

j. Ri lino makkita ri awa, ri akhera makkita ri asel Di dunia melihat ke bawah, di akhirat melihat ke atas.

k. Pallawana nabi Muhammad/Perisai nabi Muhammad

l. Narekko sikekkeng tana utiwirekki, idipa passokku I mancaji bulu. Narekko sitetti uwae utiwirekki, idipa passokkui mancaji tasi'l Jika segenggam tanah kubawa, harap anda sempurnakan menjadi gunung. Jika setitik air kubawa, harap anda sempurnakan menjadi lautan.

m. Cedde'ka ala cede naparennaja cedde' cinna mato cedde'/Hampir saja karena hal sedikit, celaka menimpa karena kemauan kecil

\section{Petuah Bijak Putri MAN 1 Bone}

a. Lele bulu tellele abiasang/Bulu itu bisa berubah warna, tapi kebiasaan tak pernah berubah. b. Malampe pappuru'/Panjang tali celana.

c. Conga ri keteng nge natosiduppa matal Mendongak pada bulan, dan kita bersua disana

d. Tedong mate riawa bolana de nitai narekko tungo mate riawa bolana tawwe nita/Sapi mati di bawah rumah sendiri tidak kelihatan, tetapi semut mati di bawah rumah tetangga malah kelihatan.

e. Laing natajeng laing napolei/Lain yang ditunggu lain yang datang.

f. Upurennui cede e napolei maegae/Syukuri yang sedikit malah datang yang banyak.

g. Bua maddenne de na mabela pole batanna/Buah yang jatuh tak jauh dari batangnya.

h. Makkabbetti tanru tedong/Mencubit tanduk kerbau.

i. Pada lao teppada upe/Sama-sama pergi (merantau) tapi tidak sama peruntungan.

j. Mali siparappe, rebba sipatokkong, malilu sipakainge/Hanyut saling menolong, Jatuh saling menegakkan, Khilaf saling mengingatkan.

\section{Petuah Bijak Santri Putra MAS PMJ Bone}

a. Siri patuoka, siri pancajika, narekko mukeccai siriku cappa kawali mabbicara/Malu yang membuatku bertahan hidup, malu yang melahirkanku, jika malu itu kau ganggu maka badik yang akan bicara.

b. Aja muatinro ko elei napittok ammengngi manu dalle'mu/Jangan tidur dikala pagi jika tak ingin rezkimu dipatuk ayam.

c. Kambetti tello cappa tanru/Bagai telur yang berada di ujung tanduk

d. Polo potona/patah pensil.

e. Taro ada temmalengkang, makkanre paku jambatang, seppipi namalara/Berkata tak bergeming, menguatnya paku jembatang, nanti patah baru berserakan.

f. Rugiwi tau mammatu-matu e, sajui tau mappattanjengnge, sapu ripalei to mappatempoel Rugilah orang yang senang menunda-nunda, rugilah orang menanti-nanti, habis jua orang yang tak menghargai waktu.

g. Lele bulu tellele abiasang, Lelei abiasangnge, abiasangtopa palelei/Berubah warna bulu tapi tidak berubah kebiasaan, Kebiasaan itu hanya bisa berubah, jika kebiasaan yang merubahnya.

\section{Petuah Bijak Santri Putri MAS PMJ BONE}

a. Narekko maeloko botting attulili dapurengnge bekka pitu/Jika engkau mau menikah maka terlebih dahulu kelilingilah dapur tujuh kali. 
b. Karame tasa'na Tanah Bone.......... (puisi perjuangan kemerdekaan)

\section{Parewa Matarenna Tau Riolota'}

Irmawati Guru MAN 1 Bone 2015

Hei, sininna atanna Paung Allahu Táala

Ana' eppona Adam

Engkalingai upasengakki

Pappasenna tau riolota'

Na idi' rupa'e

Rupa tau ri lebo'na tanae

Nasekki tau riolota makkeda:

"aja' mulolang narekko dee mubolai eppa paerwa"

Parewa matereng, pabbukka sumpanna asalamakengnge'

Salama' ri lino

Salama' ri akhera'

Parewa matarenna tau riolota'

Tennia kawali, tennia bangkung

Parewana iyyanaritu:

"Alempureng, agettengeng, reso, na siri"

\section{Asseddingenna Tau Bone (Irmawati MAN 12015}

Tau Bone tau ade'

Tau Bone tau ke siri'

Tau Bone tau malebbi

Malebbi ada-ada

Malebbi kedo ale

Pappaseng tau riolota

Pappaseng marilaleng

"taro ada taro gau"

Ugi tau Bone

Ugi ri alebbiri

Ugi ri akkitai

Eee ... Tau Bone

Ana' eppona Arung Palakka

Engkalingai

Idi tau Bone seddiki

Idi tau Bone pada manekki

Pada wanuatta

Pada sirita

Pada asseddingetta

Mali siparappe, Rebba sipatokkong, Malilu sipakainge

\section{Andi Najamuddin (Sastrawan Bugis)}

Temmasiri' kajompie

tidak malu si kacang panjang

Tenniya iyya taro jello

bukan ia yang menancapkan kayu
Iyya makkalu

ia yang menggayutnya

Tinulu laku-laku macca paggangkanna

Rajin pangkal pandai

Mali siparappe, rebba sipatokkong, malilu sipakainge, mainge mappuji, sirui menre tessiui nno

Hanyut saling menolong, Jatuh saling menegakkan, Khilaf saling mengingatkan, sadar saling mencintai, saling tarik untuk naik tetapi tidak saling tarik untuk jatuh.

Sisalai bulunna na tingkokokna berbeda penampakannya daripada bunyinya. Issengngi nenemu, Ajakkoammengngi nenena tauwwe muisseng na de muissengi nenemu Kenalilah nenekmu, Sebab jangan sampai neneknya orang kamu kenal tetapi nenekmu sendiri kamu tidak kenal.

Gellang ri watang majjekko

Gelang di batang yang bengkok

Lagu

Iyabe lale .... Sabbarakko

iyabe lale.... sabarlah dikau

Tennapodo malampe sunge'mu

semoga panjang umur

Sikki biritta madeceng

bawa berita yang baik

Ininnawa sabbarakko lolongeng gare deceng tau sabbarae

Cita-cita bersabarlah, karena akan dapat kebaikan bagi orang yang sabar

Bulu alau na tempe

lagu Bugis populer.....

\section{Alamassea-Sea}

Lagu lintas generasi yang masih dikenal siswa

Ala ma-sea-sea mua

sungguh sia-sialah

Tau na-ompori sesse' kale

bagi orang dihinggapi penyesalan

Nasaba' riwettu baiccu'na

karena pada waktu kecilnya

De' memeng naengka nagguru

benar-benar tidak pernah belajar

Baeccu' ta mitu nawedding siseng

hanya waktu kecil lah yang dapat dibentuk

Narekko matoani massussani 
jika sudah tua maka sudah susah

\section{Nasaba' maraja nawa-naaawai}

karena sudah tinggi angan-angan

\section{Enrengnge pole toni kuttue}

bahkan sudah datang pula kemalasan

Sejalan dengan kondisi bahasa daerah Bugis yang sebelumnya disebut bukan sebagai menu utama dalam interaksi orang tua dan anak, maka dalam penelusuran petuah bijak pada siswa MA pun tampak hasilnya yang begitu minim dibanding dengan hasil inventarisasi petuah bijak yang telah dibukukan. Sebagaimana termuat dalam kitab "Silasa I" yang berisi sebanyak 177 petuah bijak dan dalam kitab "300 Ungkapan Galigo" sebanyak 300 petuah bijak demikian juga petuah bijak yang terdapat dalam kitab "ada sulessana". Sebenarnya petuah bijak tersebut memang tak harus dihafalkan dan siswa menunjukkan adanya ingatan mereka terhadap petuah bijak tertentu yang tidak dapat merangkainya secara utuh, karena lupa kalimat persisnya. Sehingga jumlah 34 ungkapan/peribahasa dan beberapa lagu dan puisi yang dihimpun dari siswa MAN 1 Bone dan MAS PMJ Bone, tidak berarti bahwa hanya itulah yang pernah mereka dengarkan. Ada beberapa siswa yang berusaha mengingat-ingat petuah bijak yang disampaikan dalam upacara pernikahan baik ketika MappettuAda dan Mappacci, dan ketika disebutkan mereka bisa mengenalinya dan memahami maksudnya sebagaimana yang pernah mereka dengarkan. Seperti; Duami uwala sappo unganna panasae na belona kanukue/hanya dua yang kujadikan pagar yaitu bunga nangka dan hiasan kuku.

Selain itu, kepala sekolah MAN 1 juga menyampaikan beberapa petuah bijak Bugis yang berkaitan dengan pengembangan budaya literasi. Seperti: "resopa temmangingi na letei pammase dewata sewwae"/ hanya kerja keras yang tiada lelah yang akan memperoleh rahmat dari Sang Yang Maha Esa. Tetapi beliau mengatakan bahwa selama ini memang ia tidak membiasakan menyampaikan petuah bijak tersebut kepada siswa, dan nasehat yang disampaikan lebih banyak dalam bentuk bahasa Indonesia. Demikain juga guru-guru dalam menyampaikan materi pembelajarannya mereka tidak membiasakan menyelipkan peribahasa Bugis tertentu untuk memotivasi siswa. Apa yang diketahui siswa tentang petuah bijak Bugis adalah kebanyakan dari bawaan mereka dari hasil belajar Bahasa Daerah pada masa duduk di bangku SD/MI dan SMP/MTS.
Petuah bijak yang terhimpun dari siswa MAN 1 Bone dan MAS PMJ Bone, secara bentuk terdiri atas puisi, lagu dan peribahasa. Sumber perolehan petuah bijak tersebut ada yang menerimanya dari orang tuanya, dari guru, dari tokoh masyarakat, dari ceramah, buku pelajaran, teman dan ada yang merupakan hasil ciptaan sendiri. Adapun makna yang terkandung dalam petuah bijak berdasarkan terjemahannya terdiri atas; perjuangan kemerdekaan Indonesia, keberanian, kebersamaan dalam persatuan, moral dan pengembangan budaya liteasi.

\section{Petuah Bijak Siswa untuk Pengembangan Budaya Literasi}

Berdasarkan terjemahan dari petuah bijak yang dihimpun dari siswa MAN 1 Bone dan santri PMJ Bone, terdapat sebuah lagu Bugis kuno yang masih sangat dikenal oleh siswa dari kedua madrasah tersebut yaitu "ala massea-sea". Secara lengkap sebagai berikut:

\section{Alamassea-sea \\ Lagu lintas generasi yang masih dikenal siswa}

Ala ma-sea-sea mua

sungguh sia-sialah

Tau na-ompori sesse' kale

bagi orang dihinggapi penyesalan

Nasaba' riwettu baiccu'na

karena pada waktu kecilnya

De' memeng naengka nagguru

benar-benar tidak pernah belajar

Baeccu' ta mitu nawedding siseng

hanya waktu kecil lah yang dapat dibentuk

Narekko matoani massussani

jika sudah tua maka sudah susah

Nasaba' maraja nawa-naaawai

karena sudah tinggi angan-angan

Enrengnge pole toni kuttue

bahkan sudah datang pula kemalasan

Lagu ini dimulai dengan pernyataan bahwa sungguh sia-sianya orang yang dihinggapi penyesalaan di kala tua, bait ini mengajak siswa untuk mengintrospeksi diri lebih awal atau melakukan simulasi penyesalan secara lebih dini jika tak ingin melakukannya secara sia-sia. Hal ini juga sesuai dengan pepatah "sesal dahulu pendapatan, sesal kemudian tiada guna", yang berarti nasehat agar memikirkan masak-masak suatu perbuatan sebelum dilakukan agar tidak terjadi penyesalan di kemudian hari. Masa anak-anak memang masa 
indahnya dunia bermain, sehingga dengan hadirnya nyanyian ini menjadi peringatan begi mereka agar tidak semua waktunya dihabiskan untuk bermain saja, dan agar mempertimbangan kegiatan yang manfaatnya dapat dirasakan di masa datang untuk menghindari terjadinya penyesalan yang sia-sia.

Bait

\section{Nasaba' riwettu baiccu'na}

karena pada waktu kecilnya

\section{De' memeng naengka nagguru}

benar-benar tidak pernah belajar.

Mengungkap penyebab dari penyesalan yang sia-sia tersebut. Yaitu jika di waktu kecil dihabiskan tanpa pernah mau belajar dengan sungguh-sungguh. Hal ini juga sesuai dengan pepatah lain yang mengatakan: "belajar di waktu kecil bagai mengukir di atas batu". Bahwa belajar di waktu kecil adalah masa yang paling baik, sebab kekuatan ingatan di kala itu masih sangat besar yang digambarkan bagai mengukir di atas batu, yang berarti akan tinggal dalam ingatan dan akan berkesan dalam hati sanubari.

Bait "Hanya waktu kecil lah yang dapat dibentuk. jika sudah tua maka sudah susah, karena sudah tinggi angan-angan, bahkan sudah datang pula kemalasan". Kembali menegaskan betapa berharganya waktu masa anak-anak, sebagai kesempatan emas untuk menyusun mimpi-mimpi dan rencana masa tua. Sebab jika masa kecil berlalu tanpa banyak belajar maka di waktu tua akan sangat susah untuk belajar, sebab angan-angan sudah semakin banyak dan kemalasan semakin kuat datang menyerang. Hal ini sesuai ungkapan "belajar sesudah dewasa bagai mengukir di atas air" yang menunjukkan arti susahnya belajar di kala umur sudah tua. Ingatan sudah pendek dan apa yang dipelajari menjadi lupa untuk dilupakan.

Membangun kesadaran belajar siswa adalah hal yang harusnya terbentuk sejak dini, mendengarkan lagu motivasi belajar seperti ini dapat mendorong siswa untuk melakukan tugas belajar secara lebih sungguh-sungguh. Lagu ini, dapat diperkuat lagi dengan ingatan tentang sebuah kisah tentang orang yang merasa sangat sulit untuk menerima suatu pelajaran, dimana ketika otaknya serasa sangat buntu, ia berlari ke dalam sebuah guwa, namun di sana ia melihat sebuah hal yang menakjubkannya, ketiaka ia melihat tetes air dari atap guwa dapat melobangi batu yang ditimpanya, peristiwa ini membuatnya terhentak dan sadar akan suatu hal bahwa, betapapun kerasnya kepalanya untuk menerima sebuah pelajaran jika ia mau mengulanginya setiap saat, suatu saat akan berbekas dan tembus juga, orang tersebut disebutkan dalam kisah kemudian menjadi pintar, dan kemudian disebut sebgai Ibnu Hajar (anak batu). Kisah ini seringkali disandingkan dengan lagu ala massea-sea yang disampaikan oleh guru ketika masih duduk di bangku SD. (Wawancara, St. Aminah guru MAN: 2016).

Penanaman unsur hero atau kepahlawanan dalam kisah-kisah atau pelekatannya terhadap sebuah lagu, slanjutnya akan membentuk sebuah memori yang bersifat otomatis, yaitu ketika salah satu penggalan lagu alamassea-sea teringat di suatu masa, maka akan teringat pula tokoh Ibnu Hajar yang kembali belajar keras setelah merasa gagal dan kemudian sukses menjadi orang terpelajar karena ketekunannya dalam menuntut ilmu. Hal ini tidak sekedar menjadi ingatan bawa sadar, tetapi juga akan melahirkan perilaku imitasi sebagaimana layaknya orang mengidolakan seorang pahlawan, selalu ada kemauan untuk mengikuti dan mengamalkan apa yang dilakukan oleh pahlawan tersebut. Demikian pula sebaliknya jika suatu saat, kisah tentang hero tersebut teringat dan terkenang secara otomatis pula akan teringat lagu alamassea-sea. Pesan-pesan dalam lagu tersebut pun seolah ter-refresh dan terinstall ulang untuk kemudian memberi semangat dan motivasi ganda untuk mengamalkan pesan yang terkandung di dalamnya.

Mali siparappe, rebba sipatokkong, malilu sipakainge/hanyut saling menolong, jatuh saling menegakkan, khilaf saling mengingatkan (tidak tahu saling mecari pengetahuan). Peribahasa ini juga sangat relevan dengan budaya literasi, khususnya dalam hal mencari pengetahuan atau menuntut ilmu, bahwa seorang yang mengetahui suatu pengetahuan hendaknya rela untuk berbagi mengajari kawannya akan hal yang sudah diketahuinya. Unsur kepahlawanan juga kembali tersaji dalam hal ini, siswa teringat dengan kepintaran Kajo Laliddong yang senang berbagi dan tidak pernah tidak mampu menjawab atas pertanyaan apapun yang diberikan kepadanya. Ibaratnya Kajao Laliddong ini adalah "Abu Nawas" dari kerajaan Bone. Pada masanya, ia dikenal kritis tapi sangat santun dalam menyampaikannya. Sehingga raja senang kepadanya karena merasa tidak dipermalukan dan dihargai dengan kemampuan permainan kata-kata Kajao Laliddong yang juga biasa dikenal dengan nama Lamellong.

Selain itu, petuah bijak yang berbunyi: Tinulu laku-laku macca paggangkanna/Rajian pangkal 
pandai. Harusnya juga lebih sering diperdengarkan kepada siswa, agar mereka senantiasa senang belajar, kerena belajar adalah modal untuk mendapatkan pengetahuan. Dalam menekuni bidang pelajaran juga diharapkan siswa memiliki kesabaran yang kuat, Ininnawa sabbarakko lolongeng gare deceng tau sabbarae/ Cita-cita bersabarlah, karena akan dapat kebaikan bagi orang yang sabar. Kekuatan dalam memelihara kesabaran adalah sumber keberanian dan keteguhan menjaga cita-cita dan kebenaran yang diperjuangkan.

Melihat tantangan belajar siswa yang semakin berat dengan berbagai mata pelajaran yang harus dihadapi. Seyogyanya dorongan untuk melakukan aktivitas belajar yang penuh semangat dapat dibangun dan dibina lebih kuat. Salah satu pemicu atau daya ungkit untuk belajar lebih keras, rajin, giat dan sabar adalah dengan menyajikan petuah bijak secara konsisten dalam ucapan dan perbuatan.

Petuah bijak memang bukan satu-satunya cara untuk mengungkit semangat siswa dalam meningkatkan budaya literasi. Tetapi jawaban dari siswa siswa MAN 1 Bone dan MAS PMJ Bone yang dipilih untuk FGD petuah bijak, menunjukkan bahwa mereka yang faham petuah bijak itu juga memiliki tradisi membaca yang baik. Sebagaimana tampak dari bacaan mereka terhadap novel-novel populer yang sarat motivasi seperti karya Andrea Hirata, Habiburrahman, Oki Setiana Dewi, dan Asma Nadia. Demikian juga novel melawan takdir karya Hamdan Johannes didistribusikan beberapa kali kepada siswa karena banyaknya permintaan.

Tradisi menulis pada siswa MAN 1 Bone juga tampak menggairahkan yang ditandai dengan adanya penerbitan buku kumpulan puisi karya siswa, yang merupakan rangkaian dari kegiatan pembinaan penulisan puisi dan cerpen, aktualisasi siswa dalam acara pentas seni, peringatan hari raya merdeka, lomba karya tulis remaja dan terdapat pula tujuh buah majalah dinding sebagai media ekspresi tulisan yang bebas dan bertanggung jawab.

Demikian juga santri di MAS PMJ Bone yang dalam acara Porseni Pesantren Nasional (Pospenas) menempatkan perwakilan untuk mengikuti lomba cipta dan baca puisi. Hal ini juga merupakan rangkaian dari kegiatan pembinaan yang dilakukan, sebagaimana tampak dalam setiap kelas mereka memiliki masing-masing mading sebagai wadah ekspresi karya tulis. Salah satu mading bahkan menampilkan beberapa bahasa seperti; Arab, Inggris, China, Korea, dan India. Sayangnya ketika ditanyakan makna dari tulisan yang berbahasa Korea tak ada yang tau betul bagaimana membacanya dan apalagi artinya. Bahkan ketika diminta menghadirkan penulisnya, ternyata sumber tulisan itu juga sudah tidak diketahui lagi dari mana, hanya sedikit mengingat bahwa itu adalah cerita tentang suatu peristiwa yang memiliki makna nasehat. Sayangnya juga pada mading tersebut tidak terdapat bahasa Daerah yang harusnya mereka lebih faham dan lebih banyak memiliki perbendaharaan yang bisa mereka ungkap dalam tulisan. Semoga keadaan ini tak seperti ungkapan yang mengatakan: "yang dikejar tak didapat, yang dikandung berceceran". Bahkan ini bisa memperkaya kepribadian santri menjadi orang dengan identitas berlapis, sehingga dengannya mereka bisa lebih siap menghadapi persaingan global.

Ekspresi karya tulis siswa khususnya dalam bentuk puisi yang merupakan hasil pembacaan mereka terhadap dunia yang dihadapinya, kemudian deskripsi realitas dan dunia yang dihidupkan dalam kata-kata menggambarkan kekayaan wawasan siswa sebagai pencipta puisi (B.S., Abdul Wachid, 2005: 21). Sebagaimana tampak dalam puisi santri MAS PMJ berikut:

\section{Direngkuh Adat}

(Musliha Alwi, Ponpes Al-Junaidiyah Biru Bone)

Dari titik selatan Sulawesi

Tampak wawasan faktual nan eksotis

Berlimpah kisah berteman adat

Sekiranya bangkang

Menggulung rusuh memecah kalangan

Terpana tatkala ku lihat tradisi

Dari ujung negeri ke ujung lagi

Tak ada yang menyerupai

Ibu pohon dan bayi suci

Bersusu getah tertutup ijuk

Menjelma rahim gayutan kandung

Tak tercactat sejarah berbalas cinta

Sesama anak pohon

Ini tubuh Tarra

Passiliran

Tanah adalah wilayah

Tongkonan adalah rumah

Adat adalah keteguhan

Bumi Toraja berlangit kasta

Bangsawan dan kelas biasa

Ketika arwah menyisakan jasad

kerabat membebaskan duka

kerbau dan babi menjadi raja ratu berbobot tinggi 
Tuhan Puang Matua

Kemudi leluhur

Menanti arwah anak cucunya

Melanglang jalan

Berportal emas

Menuju puya

Tongkonan berduka

La lao langnanmo langi'

La ma'tondok daomo

Nyanyian jenazah mengiringi

Sukma yanng beranjak pergi

Tanpa membawa diri

Tinggallah kerabat berkabung tara

Berpikir panjang persiapan

Adat beradat

Rambu solo

Harus fisibel

\section{Bugis Makassar}

(Musliha Alwi, Pesantren Modern Al-Junaidiyah Biru Bone)

Tak terkirakan

Sungguh lama air itu teduh tenang

Tak berombak

Meluap membandar

Melimpah melaut

\section{Malino Mattasi'}

Berangsur-angsur air itu surut

Memperlihatkan sesuatu di bawah genangan

Berderet, bersusun

Beraneka ragam bibit, rumput, dan jenis kayu

Berkembang aneka jenis hewan

Yang kecil hingga yang sebesar-besarnya

Gunung Bawakaraeng

Puncak terdingin di Sulawesi Selatan

Gunung Latimojong

Puncak tertinggi di Sulawesi

Antara puncak itu masih di genangi air

Orang yang telah menemukan puncak memanggil

kawan dan sanak saudaranya

Latimojong dan Bawakaraeng penduduknya kunjung mengunjungi dengan rakit alakadarnya

Semua yang berada di bawah genangan terlihat ternyata sejak zaman nenek moyang orang

Bugis-Makassar telah mahir mengarungi lautan

Patoto-e Dewata Sang-Hiyang dilangit isterinya Datu Palinge penyampai maksud kepada saudaranya di Pertiwi agar datang ke Boting Langi

Setelah musyawarah mereka akhirnya mufakat menurunkan tunasnya ke dunia untuk memuja langit dan menyembah ke Pertiwi

Batara Guru anak kandung Patotoe' dan isterinya We Nyilittimo' anak kandung dari Guru RisellengSinautoja yang dianugrahi buah cinta dari pencipta Batara Lattu yang memilih bersanding dengan We Opusengngeng

Batara Lattu dikaruniai dua orang anak bagai pinang dibelah dua yang Adam bernama Sawerigading si Hawa bernama Tenriabeng dari perkawinan Sawerigading lahirlah Lagaligo

Dan hukum adat kemudian bertahta Siapa kuat, ia berkuasa Siapa lemah, ia dilanda

Jika dibandingkan dengan data petuah bijak yang diperoleh dari santri putri MAS PMJ Bone yang hanya menyumbangkan satu buah peribahasa Bugis, menunjukkan bahwa pengembangan budaya literasi tidak harus dilakukan dengan menghafalkan petuah bijak, akan tetapi yang jauh lebih penting adalah bagaimana memaknai suatu petuah bijak, dan bagaimana mengaktualisasikan dalam kehidupan yang nyata. Meskipun Musliha Alwi tidak mengungkap satupu petuah bijak dalam bahasa Bugis, tetapi puisi yang diciptakannya sangat sarat dengan nuansa khas lokal Sulawesi Selatan. Sebagaimana tampak dalam puisi tentang Tanah Toraja dan Bawa Karaeng di atas.

\section{Ekspresi Petuah Bijak untuk Pengembangan Literasi}

Petuah bijak Bugis sebagai tradisi lisan harusnya bergulir secara natural dari generasi ke generasi, sebab sejatinya kearifan lokal yang hadir sejak dahulu secara otomatis terwarisi, sebagai suatu keluhuran nilai yang memang merupakan kebutuhan untuk menjaga keutuhan generasi. Maka bisa dideteksi bahwa proses pewarisan itu berlangsung duplikatif dari masa ke masa, lalu jika di saat ini terdapat fakta dimana petuah bijak itu tidak lagi seutuhnya sampai kepada generasi pelajar, berarti duplikasi porses pewarisan itu harus menjadi sorotan lebih tajam, tentang bagaimana sebenarnya bentuk pewarisan yang selama ini berlangsung, dan mengapa kemudian proses itu tidak lagi berjalan sebagaimana sebelumnya.

Sudah menjadi pengetahuan umum bahwa institusi keluargalah yang sejak dulu memiliki peran 
vital dalam menjaga ketahanan budaya, demikian halnya dalam proses pewarisan suatu tradisi atau kearifan lokal dan khususnya petuah bijak. Pergeseran budaya sudah sangat sering disimpulkan sebagai dampak dari modernisasi yang datang tak terbendung, segala hal yang bersifat tradisional seolah menjadi anti modernisasi dan ramai-ramai ditinggalkan. Sehingga pemulihan situasi melemahnya tradisi luhur akibat serbuan modernisasi, seyogyanya disikapi dengan memperkuat pertahanan budaya yang masih ada dan melakukan counter attack terhadap sisi-sisi modernisasi yang bersifat kontra terhadap kearifan lokal. Semoga tak semua aspek yang dibawa oleh modernisasi tidak harus bertentangan dengan kearifan lokal, dan dapat ditemukan sebuah kompromi yang bisa menjadi jalan keluar agar budaya tetap terjaga sambil tetap juga dapat dinikmati gemerlapnya kemjuan modernisasi.

Dalam konteks global, globalisasi tak pernah benar-benar melumat habis tradisi. Di wilayah dunia lain, Eropa Barat dan Amerika Utara, transisi nyata yang diharapkan dari tradisi ke modernitas tidak pernah terjadi. Sebagai norma, tradisi berlanjut untuk mendesakkan keberadaan mereka sebagai perwakilan aktif dalam menentukan bentuk khas modernitas, dan implikasinya, proses modernisasi itu sendiri secara berkelanjutan dipaksa menerima keragaman bentuk budaya yang berakar dalam tradisi tertentu (Tu Wei-Ming, 2011: 381).

Fakta bahwa beberapa siswa merasa terbantu dengan adanya pelajaran muatan lokal bahasa daerah, yang diantara materinya menyajikan petuah bijak, tidak lantas dapat dijadikan acuan untuk menambah jam pelajaran untuk itu. Beban kurikulum sekolah sudah terlalu berat, dan akan menjadi lebih berat lagi jika harus ditambah dengan mata pelajaran petuah bijak, meskipun itu dianggap sangat urgen dan mendesak untuk menjadi bagian dari solusi terhadap segala macam problematika kenakalan remaja dan ketertinggalan siswa dalam budaya literasi. Selain itu, tuntutan kurikulum sekolah jangan sampai dirongrong oleh keinginan untuk memasukkan berbagai ide pembelajaran yang semuanya dianggap urgen, ketika korupsi tak kunjung dapat teratasi dan tumbuh semakin subur bukan berarti materi pelajaran korupsi harus masuk juga dalam kurikulum, demikian juga dengan masalah pelanggaran lalu lintas yang dianggap banyak terjadi karena kekurang tahuan masyarakat terhadap aturan lalu lintas, tidak juga bijak jika solusi yang disodorkan agar materi lalu lintas masuk dalam kurikulum.
Petuah bijak kembalilah bijak menekuri diri sebagai suatu yang melekat pada identitas pelaku budaya, dalam artian masyarakat yang di dalamnya keluarga, dan keluarga yang di dalamnya adalah orang per orang. Maka setiap orang harus merasa sebagai bagain inti dari kebudayaannya. Orang per oranglah yang menelurkan budaya petuah bijak itu, mendekapnya dengan penuh kehangatan kasih sayang dan menetaskannya dengan sempurna, sehingga kemudian lahir anak-anak yang kuat dengan kekuatan warisan budaya yang melekat menjadi identitas asli sebagaimana genetika dari orang tuanya.

Hanya kesadaran budaya dengan gerakan orang per orang yang bisa menyelamatkan tradisi petuah bijak dari kepunahannya. Sebab demikianlah proses petuah bijak itu bergulir dari masa ke masa, tidak dengan formalitas semu dan malah mengaburkan nilainya, sebab kearifan lokal tidak dapat dinilai dengan adanya siswa menghafalkannya sehingga ia mendapat nilai tinggi. Ia hanya dapat diterima dari hati dan dengan hati. Penyampaian yang dilakukan sambil lalu dan sekedarnya saja tak akan banyak membantu dan tidak meyakinkan untuk dapat dimanfaatkan. Bukan berarti petuah bijak tidak bisa diajarkan, sebab pada dasarnya ia banyak lahir dari kearifan sang guru. Tetapi momentum penyampaian dan pengajarannya harus bersesuaian antara situasi dan pesan dari petuah bijak tersebut. Bukan pada tempatnya menyampaikan petuah bijak "biar lambat asal selamat" kepada seseorang yang akan mengikuti lomba lari.

Meskipun bukan solusi untuk memasukkan petuah bijak dalam mata pelajaran di sekolah, tetapi bukan pula haram untuk menyelipkannya dalam proses pengajaran di sekolah. Sebagaimana diyakini bahwa petuah bijak adalah identitas melekat pada setiap orang, maka setiap orang berpeluang untuk menelurkannya dalam profesi apapun yang melingkupinya. Sehingga seorang guru matematika, tak melulu seratus persen pengajarannya adalah matematika, satu tambah satu sama dengan dua, jika budi mempunyai 2 kelereng kemudian dia mencuri 1 kelereng temannya berapa jumlah kelereng budi, maka pada momen inilah petuah bijak

\section{PENUTUP}

Petuah bijak yang dihimpun dari siswa MAN 1 Bone dan santri PMJ Bone secara bentuk terdiri atas; puisi, lagu dan peribahasa. Sumber perolehan petuah bijak tersebut ada yang menerimanya dari 
orang tuanya, guru, tokoh masyarakat, ceramah, buku pelajaran, teman dan ada yang merupakan hasil ciptaan sendiri. Adapun makna yang terkandung dalam petuah bijak berdasarkan terjemahannya terdiri atas; perjuangan kemerdekaan Indonesia, keberanian, kebersamaan dalam persatuan, moral dan pengembangan budaya liteasi.

Adapun petuah bijak yang dapat di gunakan untuk mengembangkan budaya literasi siswa MA adalah lagu "ala massea-sea" yang isinya mengandung nasehat untuk belajar diwaktu kecil agar tidak merasakan sia-sianya penyesalan di kala sudah tua. Lagu ini juga memiliki unsur hero atau kepahlawanan seorang tokoh yang disebut Ibnu Hajar, dimana ia terkenal dapat menjadi orang berilmu tinggi akibat kesungguhan dan kegigihannya dalam belajar setelah sempat merasakan kegagalan dan bangkit karena melihat tetesan air dalam guwa yang dapat menembus batu.

\section{UCAPAN TERIMA KASIH}

Saya mengucapkan terima kasih kepada Kepala Balai Penelitian dan Pengembangan Agama Makassar yang telah memberikan tugas kepada saya untuk melakukan penelitian ini di Kabupaten Bone, Sulawesi Selatan. Terima kasih juga saya ucapkan kepada Kepala MAN 1 Bone dan Kepala MAN PMJ Bone, serta para siswa dari kedua madrasah tersebut yang telah memberikan bantuannya selama penelitian ini dilakukan. Saya ucapkan terima kasih tak terhingga secara khusus kepada para peneliti Litbang Agama Makassar atas segala kritik dan saran untuk perbaikan penulisan artikel ini.

\section{DAFTAR PUSTAKA}

Danandjaja, James. 2007. Folklor Indonesia. Jakarta: Grafiti.

Hutomo, Suripan Sadi. 1991. Mutiara yang Terlupakan, Pengantar Studi Sastra Lisan. Jawa Timur: Himpunan Sarjana Kesusastraan Indonesia.

Kusumo, Ganang Probo. 2013. Pengembangan Literasi
Akademik Siswa di Sekolah. Skripsi, Bahasa, dan Sastra Indonesia. Universitas Negeri Malang.

Latifah. 2014. "Analisis Literasi Media Televisi Dalam Keluarga. Studi Kasus Pendampingan Anak Menonton Televisi di Kelurahan Sempaja Selatan Kota Samarinda". eJournal Ilmu Komunikasi, Volume 2, Nomor 4. 259-268.

Lia,Linda. 2015. "Multimedia InteraktifSebagai Salah Satu Alternatif Pembelajaran dalam Bidang Pendidikan Sains". Jurnal Inovasi Dan Pembelajaran Fisika, Volume 2, Nomor 2, November 2015. Sumatera Slatan: Program Studi Pendidikan Fisika FKIP Universitas Sriwijaya (UNSRI).

Priatno, Basuki. 2013. Analisis Literasi Kritis Puisi Puisi Taufiq Ismail Dalam Kumpulan Puisi Malu (Aku) Jadi Orang Indonesia Yang Merepresentasikan Kekuasaan Dan Memanfaatannya dalam Pembelajaran Puisi di SMA Negeri 1 Damangan Purwakarta. Bandung: Universitas Pendidikan Indonesia.

Rahman, Alwy. 2016. Saying, Materi pada Seminar Internal Bidang Lektur Litbang Agama Makassar.

Ratna, SU. Nyoman Kutha. 2011. Antropologi Sastra: Peranan Unsur-unsur Kebudayaan dalam Proses Kreatif. Yogyakarta: Pustaka Pelajar.

Sari, Esti Swatika. 2015. judul Mengoptimalkan Kembali Literasi Sastra Di Perguruan Tinggi, Perlukah?. Prosiding Konferensi Nasional. Bahasa Dan Sastra Iii. Surakarta, 30 - 31 Oktober. Surakarta: Pascasarjana Universitas Sebelas Maret.

Suyono. 2015. "Pembelajaran Efektif dan Produktif Berbasis Literasi: Analisis Konteks, Prinsip dan Wujud Alternatif Strategi Implementasinya di Sekolah”. Jurnal Bahasa dan Seni, tahun 37. Nomor 2.

Syukran, Muhammad Adib. 2014. Pengembangan Buku Ajar Kimia Sub Topik Protein Menggunakan Konteks Telur Untuk Membangun Literasi Sains Siswa SMA. Bandung: Universitas Pendidikan Indonesia

Tu We-Ming, 2011. Modernisasi Berlipat Ganda: Penyelidikan Pendahuluan ke dalam Implikasi Modernitas Asia Timur, dalam Kebangkitan Peran Budaya, Bagaimana Nilai-nilai Membentuk Kemajuan Manusia. Jakarta: Pustaka LP3ES

Wachid, Abdul, 2005. Sastra Pencerahan, Yogyakarta: Centra Grafindo. 